\title{
Solder reflow process induced residual warpage measurement and its influence on reliability of flip-chip electronic packages
}

\author{
Se Young Yang ${ }^{\text {a }}$, Young-Doo Jeon ${ }^{\mathrm{b}}$, Soon-Bok Lee ${ }^{\mathrm{a}, *}$, Kyung-Wook Paik ${ }^{\mathrm{b}}$ \\ a Department of Mechanical Engineering, Korea Advanced Institute of Science and Technology, 373-1 Guseong-dong, \\ Yuseong-gu, Daejeon 305-701, Republic of Korea \\ ${ }^{\mathrm{b}}$ Department of Material Science, Korea Advanced Institute of Science and Technology, 373-1 Guseong-dong, Yuseong-gu, \\ Daejeon 305-701, Republic of Korea
}

Received 13 May 2004; received in revised form 8 May 2005

Available online 16 September 2005

\begin{abstract}
To meet the future needs of high pin count and high performance, package size of flip-chip devices is constrained to become larger. In addition, to fulfill the environment issues, lead free solders will be replacing lead contained eutectic $(\mathrm{Sn} / 37 \mathrm{~Pb})$ in near future. Thus, in this work, the effect of residual warpage and consequent residual stress on the reliability of large flip-chip using lead free solder is examined. Several effective experimental approaches to accurately measure residual warpage, using Moiré interferometry, shadow Moiré, and image processing schemes, are introduced. Moreover, geometric, process, and material parameters affecting the residual warpage during reflow process are discussed and some modifications are suggested. Finally, it is verified that it is crucial to accurately quantify and control the residual warpage in order to guarantee the overall reliability of flip-chip packages regardless of presence of underfill. (C) 2005 Elsevier Ltd. All rights reserved.
\end{abstract}

\section{Introduction}

Flip-chip on board (FCOB) technology possesses the highest packaging density compared with other electronic packaging approaches, and is expected to become a mainstream technology in the near future [1]. It attracts increasing attention from the electronic packaging industry due to their good thermal performance, smaller size, lower profile, lighter weight, higher I/O density, high speed, low inductance, fine pitch, etc. [2-4]. How-

\footnotetext{
* Corresponding author. Tel.: +82 42869 3029; fax: +82 42 8693210.

E-mail address: sblee@kaist.ac.kr (S.-B. Lee).
}

ever, the difference in the coefficient of thermal expansion (CTE) between the chip and the substrate makes flip-chip configurations vulnerable to thermally induced strains and often results in solder joint fatigue [5]. As an effective solution, filling the space between the silicon die and PCB with underfill encapsulant mechanically couples the severely CTE mismatched chip and substrate and provides a significant (at least one order of magnitude) enhancement in solder joints reliability [3,5-7,912]. This mechanical coupling between the die and the substrate reduces the strain in the solder connections by additional load transfer through the shear stresses, thus enhancing the thermomechanical reliability of flip-chip assembly [13]. Extensive studies have already made clear that the thermal fatigue life of the solder 
joints can be greatly improved when the underfill material has a low CTE, a high Young's modulus and a high glass transition temperature $\left(T_{\mathrm{g}}\right)$ [14-16].

However, even with underfill, the reliability of solder joints is still a serious concern in FCOB assembly $[17,18]$. The accurate failure prediction of solder joints may be hindered by factors such as underfill imperfection $[10,12,19-22]$ or assembly process induced residual stresses $[11,23,24]$. In this study, the latter is focused for closer analysis, especially during solder reflow process which appears to be more severe when $\mathrm{Sn} / 37 \mathrm{~Pb}(\mathrm{SP})$ is replaced to $\mathrm{Sn} / 3.0 \mathrm{Ag} / 0.5 \mathrm{Cu}(\mathrm{SAC})$, lead free solders. This is ascribed to the inherent material behavior of SAC which tends to creep and relax less than SP at low stress levels [25-28] which will be discussed further in Section 2.2.

Most of existing works to predict effects of sequential processing steps on manufacturing stresses or deformations, are based on non-linear visco-plastic numerical analysis [23,24,28-32]. Although there exist some experimental works to directly measure residual warpage and stresses during fabrication process $[3,11,33,34,59]$, not many of them have mainly focused on soldering process, neither have addressed a direct comparison between lead contained and lead free solders. Polsky et al. [35], Stiteler et al. [36], and Chien et al. [37] have investigated the warpage behavior of packages or PCBs during soldering processes, however, the works are primarily interested in the warpage of substrate or package themselves under reflow history rather than the warpage induced due to mechanical coupling of chip and substrate through solder.

There exist various techniques in order to accurately measure warpage of chip or substrates. Covering the recent works, geometric Moiré [38] methods, including shadow Moiré [35-37,39-42] and projection Moiré [41], in-plane Moiré interferometry [43-50], TwymanGreen (Michelson) interferometry [34,51,52], Fizeau interferometry $[53,54]$, stylus scratch method [58], touch probe method [32] and laser profilometry $[55,56]$ are well developed and frequently applied methods in electronic packaging field. Each technique comprises of both merits and demerits at the same time, thus, one should carefully decide considering effectiveness to one's own engineering application. Pioneer works of late 1980s and early 1990s, especially on optical methods, are well summarized by Suhling [57].

In this work, in-plane Moiré interferometry in company with newly developed image processing filter is applied to measure residual warpage of flip-chip after solder reflow process. The amount of warpage is relatively small, happening to occur between 0 and $10 \mu \mathrm{m}$, which is too little to apply conventional geometric Moiré methods. For verification, alternative experimental approaches are performed. Adopting in-plane Moiré interferometer and thermal optical chamber, residual warpage is estimated by in situ measurement of $V$-displacement field while heating the package up to its full relaxation. For $\mathrm{SAC}(\mathrm{Sn} / 3.0 \mathrm{Ag} / 0.5 \mathrm{Cu})$ which does not relax even up to $175^{\circ} \mathrm{C}$ of heating, shadow Moiré technique with fine grating ( $5 \mu \mathrm{m}$ pitch) is applied to evaluate its residual warpage. In addition, the effect of material property (SAC vs. $\mathrm{SP}(\mathrm{Sn} / 37 \mathrm{~Pb})$ ) of solders on residual warpage is emphasized. It is discovered that residual warpage and stresses induced during solder reflow process significantly affects the entire reliability of flip-chip regardless of presence of underfill.

\section{Experiments and results}

\subsection{Flip-chip assembly}

The flip-chip package studied in this work is composed of silicon chip, C4 solder joints, and PCB substrate (Fig. 1). The chip has a side dimension and thickness of $10.0 \mathrm{~mm}$ and $0.685 \mathrm{~mm}$, respectively. Single

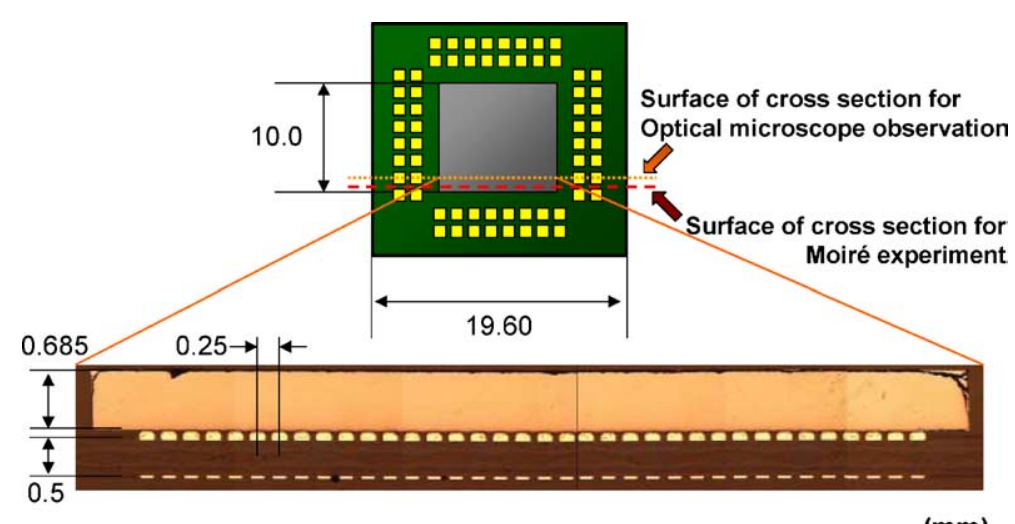

$(\mathrm{mm})$

Fig. 1. Flip-chip assembly design. 
row $144 \mathrm{I} /$ Os are distributed at the peripheral of the chip with $0.25 \mathrm{~mm}$ pitch, $0.12 \mathrm{~mm}$ pad size, and $0.095 \mathrm{~mm}$ passivation openings. $19.6 \mathrm{~mm}^{2} \mathrm{PCB}$ substrate of $0.5 \mathrm{~mm}$ thickness is designed with four point probe daisy chains so that electrical connection of 16 solders located at each corners can be monitored. Electrical resistance of solder joints is measured at room temperature in between certain number of cycles. Solder pastes, SP and SAC alloys, are screen-printed on electroless $\mathrm{Ni}-\mathrm{P}$ UBMs resolving low-cost and simple flip-chip bumping. Five microns of $\mathrm{Ni}-\mathrm{P}$ layer and $0.08 \mu \mathrm{m}$ of $\mathrm{Au}$ layer are plated on Al pads where solder bumps of $120 \mu \mathrm{m}$ diameter are fabricated subsequently. The solder bumps on $\mathrm{Si}$ chip are dipped into a flux and then aligned to the substrate using flip-chip bonder. Soldering was performed using a reflow module on the flip-chip bonder with peak temperature of $230^{\circ} \mathrm{C}$ and $280^{\circ} \mathrm{C}$ for $\mathrm{SP}$ and $\mathrm{SAC}$, respectively. Reflow of each solder was performed as followed processes:

1. Flux activation at $150{ }^{\circ} \mathrm{C}$ for $1 \mathrm{~min}$.

2. Solder melting at peak temperature for $1 \mathrm{~min}$.

3. Air cooling to room temperature.

Finally, flux cleaning is followed in DI (deionized) water at $60{ }^{\circ} \mathrm{C}$.

\subsection{Moiré experiment}

Moiré interferometry is a whole-field in-plane displacement optical measurement technique with both high displacement sensitivity and high spatial resolution. It is especially effective for the non-uniform in-plane deformation measurements and has been used in the research and development of microelectronic packages to measure thermally induced displacement fields.

A thin cross-line diffraction grating is replicated onto the cross-section of interest and deforms with the sam- ple. Interaction between two coherent laser beams with the deformed grating produces an interference pattern representative of the thermally induced displacement field. Based on a grating frequency, $f$ of 1200 lines/ $\mathrm{mm}$, each interference fringe spacing represents $417 \mathrm{~nm}$ relative displacement difference which explains the definition of sensitivity [38]. Thermally induced deformations can be extracted from the displacement fields by the following relationship:

$U(x, y)=\frac{1}{f} N_{x}(x, y)$
$V(x, y)=\frac{1}{f} N_{y}(x, y)$

where $N_{x}$ and $N_{y}$ are the fringe orders in $U$ and $V$ fields, respectively.

In order to measure the residual warpage of chip and PCB after soldering process, bare chip and PCB are cross-sectioned and polished separately until the flat surface is guaranteed as in Fig. 2(a). They are polished in such a way that surface of cross-section is controlled to be shown in Fig. 1. The surface does not include solder bumps. Since warpage is a global deformation which occurs mainly due to chip and PCB CTE mismatch the presence of solder in the measured surface would not affect the value significantly. After polishing, a 1200 lines/ $\mathrm{mm}$ cross-line diffraction grating is replicated on the cross-section of interest using TRA-BOND F114 epoxy as shown in Fig. 2(b). The epoxy has $T_{\mathrm{g}}$ of $128^{\circ} \mathrm{C}$ and operation temperature range varies from $(-) 60^{\circ} \mathrm{C}$ to $(+) 130^{\circ} \mathrm{C}$. The replication is performed at room temperature $\left(23^{\circ} \mathrm{C}\right)$ and cured for $24 \mathrm{~h}$. The thickness of epoxy is extremely lower than the specimen. It is controlled to be below $5 \mu \mathrm{m}$. Its modulus is also an order lower than packaging materials. Thus the deformation of epoxy is thoroughly confined to that of the specimen. Situation is preferable if temperature exceeds the $T_{\mathrm{g}}$ of the epoxy since the modulus of epoxy is further decreased.

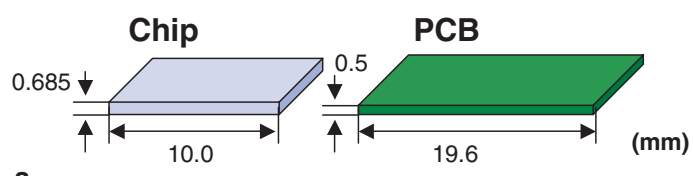

a

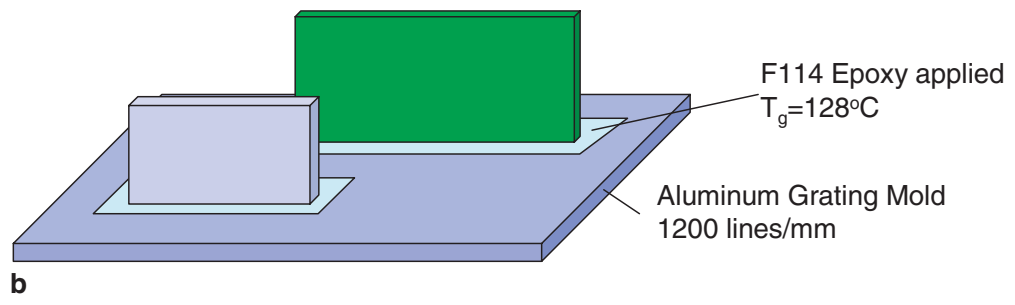

Fig. 2. Specimen preparation for Moiré experiment: (a) separate polishing for chip and PCB; (b) separate diffraction grating replication at room temperature $\left(23^{\circ} \mathrm{C}\right)$. 
However, epoxy will not reflect the deformation of the specimen in case the adhesion is lost. The adhesion of the epoxy is guaranteed by several pretests. It lasted for 4000 cycles from $(-) 50{ }^{\circ} \mathrm{C}$ to $(+) 150{ }^{\circ} \mathrm{C}$.

After confirming the null field of each adherends, the chip and PCB are bonded by solder reflow process as mentioned in previous section. Figs. 3 and 4 reveal the residual warpage ascribed to mechanical coupling of chip and substrate through soldering process measured by in-plane Moire system. The convex type warpage, which can be calculated by counting the fringes from $V$ field, is observed for both chip and PCB where severe warpage is apparent for SAC compared to SP. This is ascribed to the inherent material behavior of SAC which tends to creep and relax less than SP at low stress levels, which is well defined from quantitative studies of various works [25-28]. Sasaki et al. [28] has performed actual stress relaxation test which confirms this argument. In addition, Wiese et al. $[25,26]$ and Amagai et al. [27] have found out with their well-controlled creep tests that SAC creeps less than SP. The fact that SAC experiences larger cooling $\Delta T$ excursion during reflow history also contributes to this existing state. The war-
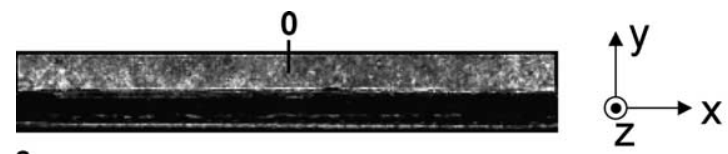

a

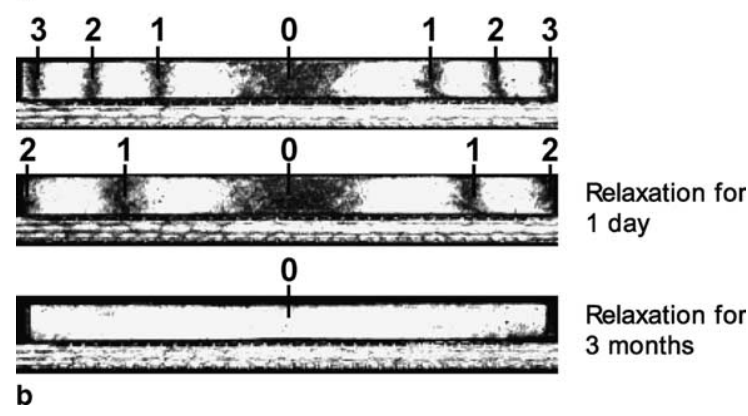

Fig. 3. Residual warpage measurement after solder reflow process: (a) $\mathrm{SP}(\mathrm{Sn} / 37 \mathrm{~Pb})$ chip; (b) $\mathrm{SAC}(\mathrm{Sn} / 3.0 \mathrm{Ag} / 0.5 \mathrm{Cu})$ chip.

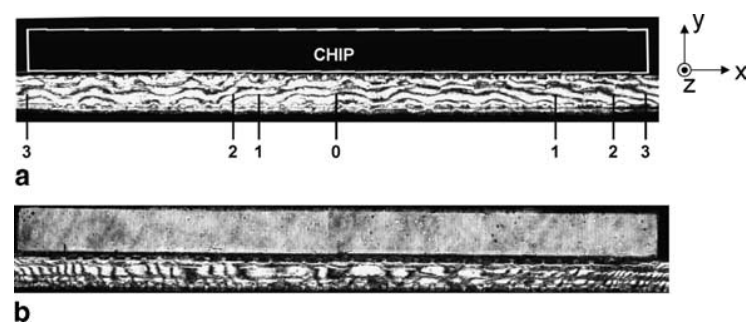

Fig. 4. Residual warpage measurement after solder reflow process: (a) $\mathrm{SP}(\mathrm{Sn} / 37 \mathrm{~Pb}) \mathrm{PCB}$; (b) $\mathrm{SAC}(\mathrm{Sn} / 3.0 \mathrm{Ag} / 0.5 \mathrm{Cu})$ PCB. page of chip and substrate are acquired independently since the plane of incidence is slightly different due to separate polishing.

In case of SP, chip is observed to have no warpage (Fig. 3(a)) while there exists slight amount of $1.251 \mu \mathrm{m}$ for PCB (Fig. 4(a)). This reflects the fact that, as it was expected, chip is readily flattened back owing to its high bending stiffness originated in high Young's modulus and large thickness compared to PCB. In case of SAC (Fig. 3(b)), chip is slightly warped about $1.293 \mu \mathrm{m}$ at the beginning of measurement (several hours after solder reflow). However, the warpage is gradually mitigated due to relaxation of residual stress at solder and finally disappears after 3 months of storage at room temperature.

The warpage of PCB for SAC, as shown in Fig. 4(b), contains many low frequency noises which may have arisen from higher temperature exposure during reflow process. Inspecting the dark noise region applying highly magnifying zoom lens $(3.0 \mathrm{~mm}$ field of view with $640 \times 480$ pixel CCD camera) with higher NA (numerical aperture) and enhancing the illuminance, it is affirmed that the fringe connectivity is maintained. This implies that the noises are the result of local residual out-of-plane deformation (direction normal to the plane of cross-section, $z$-direction) of PCB rather than specimen grating deterioration. The out-of-plane deformation of substrate which is postulated to become abruptly accelerated between $230^{\circ} \mathrm{C}$ and $280^{\circ} \mathrm{C}$, locally varies the incident plane angle from previous cross-sectioned plane and gives rise to low frequency noises.

\subsection{Phase shifting filter}

In order to accurately quantify the warpage amount for PCB of SAC an image processing filter is developed, namely, the phase shifting filter. The main concept of the proposed imaging filter is to classify the intensity value rather it is a noise or a data at $(i, j)$ th pixel. Intensity of a Moiré fringe pattern can be expressed in following tensor equation:

$I_{i j}^{k}=D_{i j}+A_{i j} \cos \left(\phi_{i j}-\delta_{k}\right)$

where $i$ and $j$ are the indexes for $x$ and $y$ pixel in the image and $k$ is for the phase shift. $I_{i j}$ denotes the intensity value from the fringe pattern, $\phi_{i j}$ is the phase value at corresponding pixel, $\delta_{k}$ is the phase shifting amount, $D_{i j}$ is the mean intensity or the background intensity, and $A_{i j}$ is the visibility. The intensity value of $(i, j)$ th pixel will follow Eq. (3) and alter when it is phase shifted due to change in $\delta_{k}$ (Fig. 5(b)). However, it will remain constant if the intensity value at $(i, j)$ th pixel is a noise as in Fig. 5(a). A variance is defined which reflects the degree of difference between the original image and the phase shifted images. 


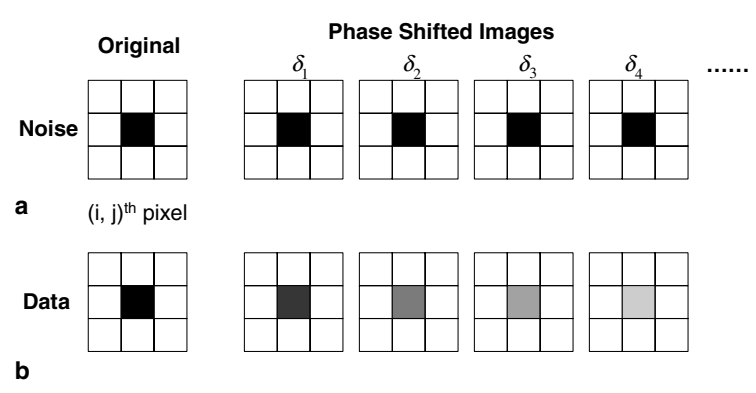

Fig. 5. Conceptual idea of phase shifting filter-intensity variation respect to consecutive phase shifts: (a) case when $(i, j)$ th pixel is a noise; (b) case when $(i, j)$ th pixel is a data.

The total variance at $(i, j)$ th pixel, $V_{i j}$ is defined to be the sum of variance at each phase shifted steps and can be expressed by the following:

$V_{i j}=\sum_{k=1}^{N}\left(\left(I_{i j}^{0}-I_{i j}^{k}\right)^{2}\right)$

where $N$ refers to total number of phase shifts within a single phase travel, $I_{i j}^{k}$ is the intensity of $k$ th phase shift, and $I_{i j}^{0}$ is the original image without any phase shift. Process algorithm is depicted in Fig. 6, where $V_{\text {thres }}$ is the threshold variance determined arbitrarily by the user considering the noise level. Fig. 7 shows the residual warpage ( $V$ field) of PCB under the chip for SAC where the phase shifting filter is applied to enhance the accuracy in counting the fringe order. The total number of phase shifts, $N$ is equal to 13 for current analysis. Reference grating is phase shifted with PZT driven actuator in in-plane interferometer system. The pixels which have $V_{i j}$ lower than $V_{\text {thres }}$ are defined as noises. They are flagged by designating the intensity value as 255 which is revealed as white dots in Fig. 7. From the original image where it is impossible to perform accurate fringe counting, feasible fringe counting is possible after the filtering. In some cases, multi-filtering with two different thresholds should be performed to increase the accuracy as in Fig. 7(a). The amount of warpage is estimated to be $7.089 \mu \mathrm{m}$ which is about five times larger than that of SP. There exist warpage difference in right and left half of PCB. Usually, flexible substrates including thin PCB does not warp symmetrically. Especially, for such cases

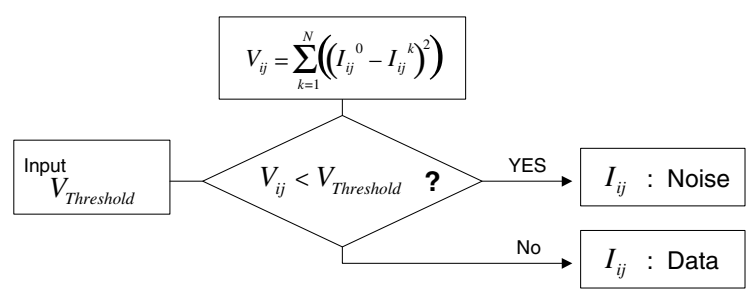

Fig. 6. Process algorithm (flow chart) for phase shifting filter.

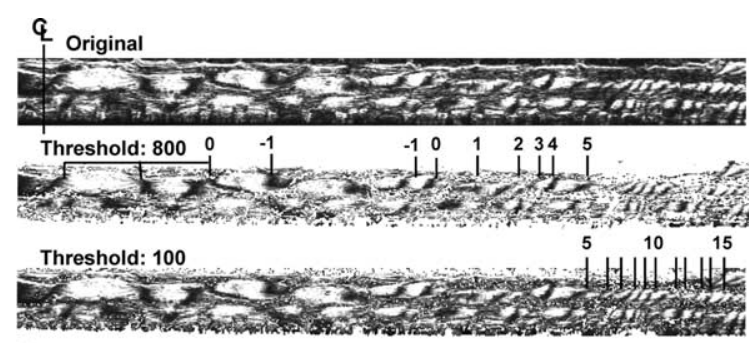

a

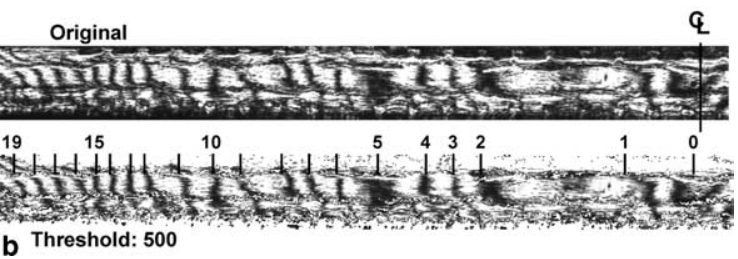

Fig. 7. Application of phase shifting filter in counting the fringes for residual warpage of SAC PCB: (a) right half of PCB; (b) left half of PCB.

where solder is bonded peripherally without underfill, high asymmetric is expected.

\subsection{Verification of warpage measurement through thermal relaxation}

An alternative experiment with both SP and SAC is performed to verify the residual warpage measured in previous section. Different from the former experiment grating is replicated at room temperature after the chip and PCB are bonded through solder reflow process. Thus, the convexly warped state is set as reference as shown in Fig. 8(a). As the specimen is heated from room temperature to $125^{\circ} \mathrm{C}$, the warped chip and PCB will gradually relax and become flat due to relaxation behavior of solder. This flattening will appear as concave bending in Moiré fringes as in Fig. 8(b). Relaxation behavior of warpage is expected to saturate and converge to a certain value when it becomes completely flat upon full relaxation. Thermal relaxation procedure can also be achieved by imposing prolonged holding time at considerably high temperature. However, it also

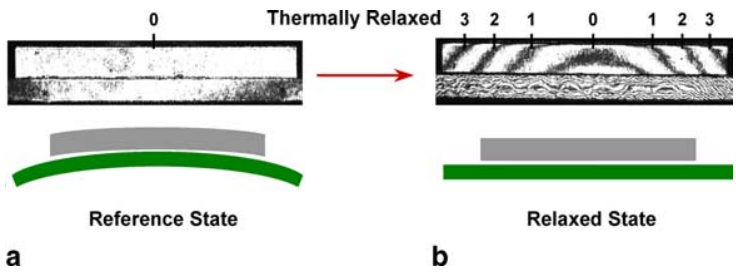

Fig. 8. Residual warpage measurement through thermal relaxation: (a) reference state: convexly warped state; (b) seemingly, concavely warped state: flattened state. 
requires certain degree of bending stiffness of the adherends to become flat.

In order to resolve deformation behavior during high temperature condition the Moiré system is connected to the optical environmental chamber (EC1A, Sun Systems) as in Fig. 9. The air inside the chamber must be circulated vigorously to achieve the heating/cooling rate and maintain isothermal condition. Consequently, the environmental chamber experiences vibrations, which are normally transmitted to the specimen. However, vibrations can be tolerated if there is no relative motion,

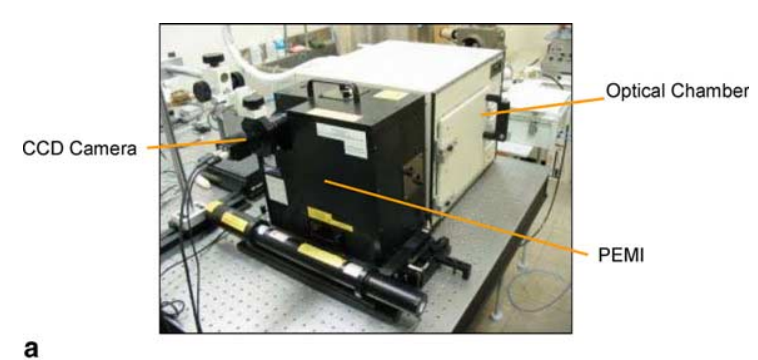

a

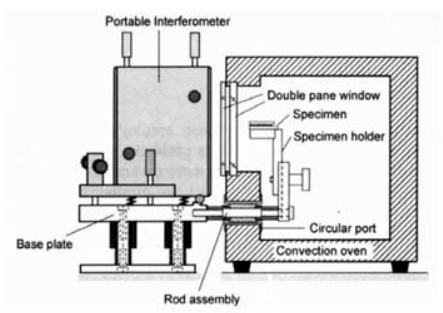

b

Fig. 9. Experimental setup for thermal relaxation test: (a) setup feature; (b) schematic design view (adapted from [45]). i.e., if the specimen and the optical system vibrate in unison. To fulfill this requirement, the specimen holder is connected directly to the interferometer and it is essentially free from the chamber [45].

In Fig. 10, results clearly reveal that the amount of residual warpage is in quite good agreement with the values obtained in previous section for SP chip, SP PCB, and SAC chip. However, for SAC PCB, low bending stiffness of $\mathrm{PCB}$ as well as low degree of relaxation behavior of SAC hinder the full relaxation. It failed to relax fully, even at $175^{\circ} \mathrm{C}$ with 30 min holding time (Fig. 11). Accurate warpage above $175^{\circ} \mathrm{C}$ was unattainable due to poor spatial resolution caused by high coefficient of thermal expansion (CTE), $\alpha_{y}$ of PCB which resulted in excessive thermal deformation in $y$-direction as shown in Fig. 11.

\subsection{Fine pitch grating shadow Moiré}

As an alternative solution to quantify the residual warpage of SAC PCB, a shadow Moiré setup is developed. This, non-contact, simple, and relatively low cost setup provides whole-field fringe pattern of out-of-plane displacement. A Moiré pattern is a visual pattern produced by the superposition of two regularly spaced gratings that geometrically interfere to create light and dark fringes [35]. The shadow Moiré method uses a reference grating which is placed directly in front of a test object or specimen. The shadow of reference grating on the specimen, generated from transmitting a collimated beam of light through the grating, produces a virtual grating, termed specimen grating [17]. When the surface under investigation is inclined or curved, shadow Moiré fringes are formed by interaction between these two

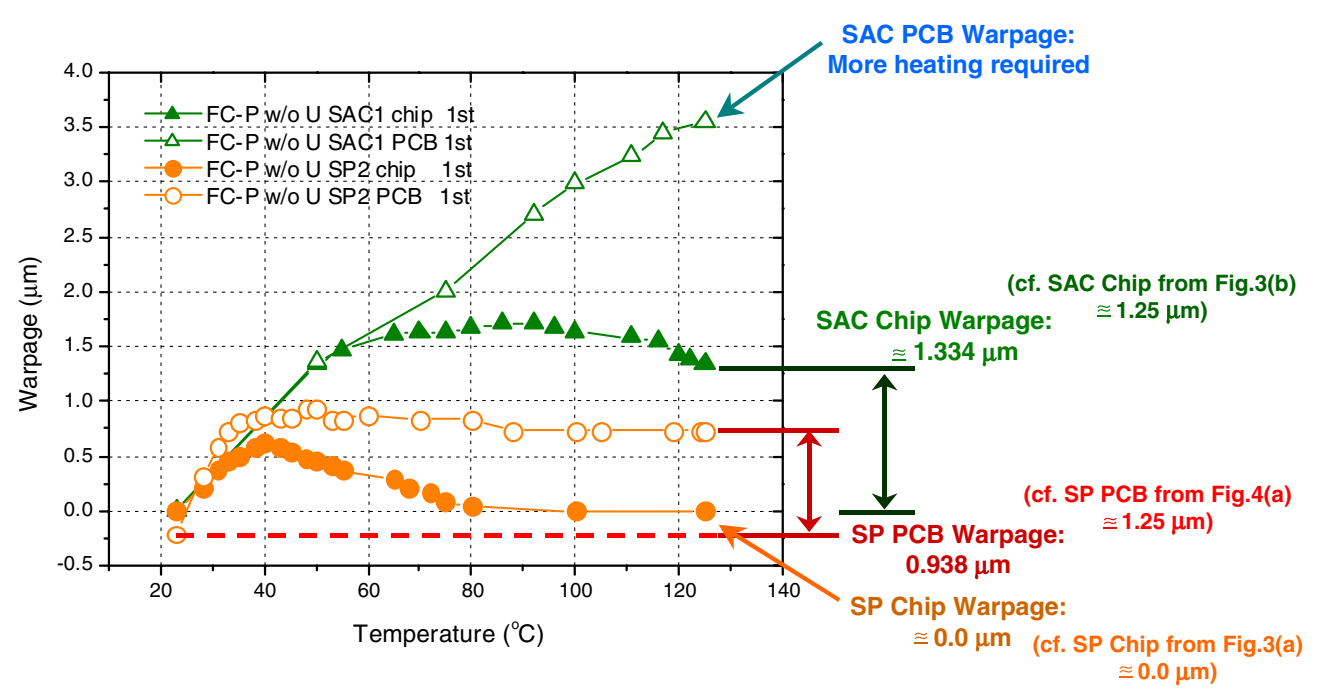

Fig. 10. Residual warpage measured by thermal relaxation test. 


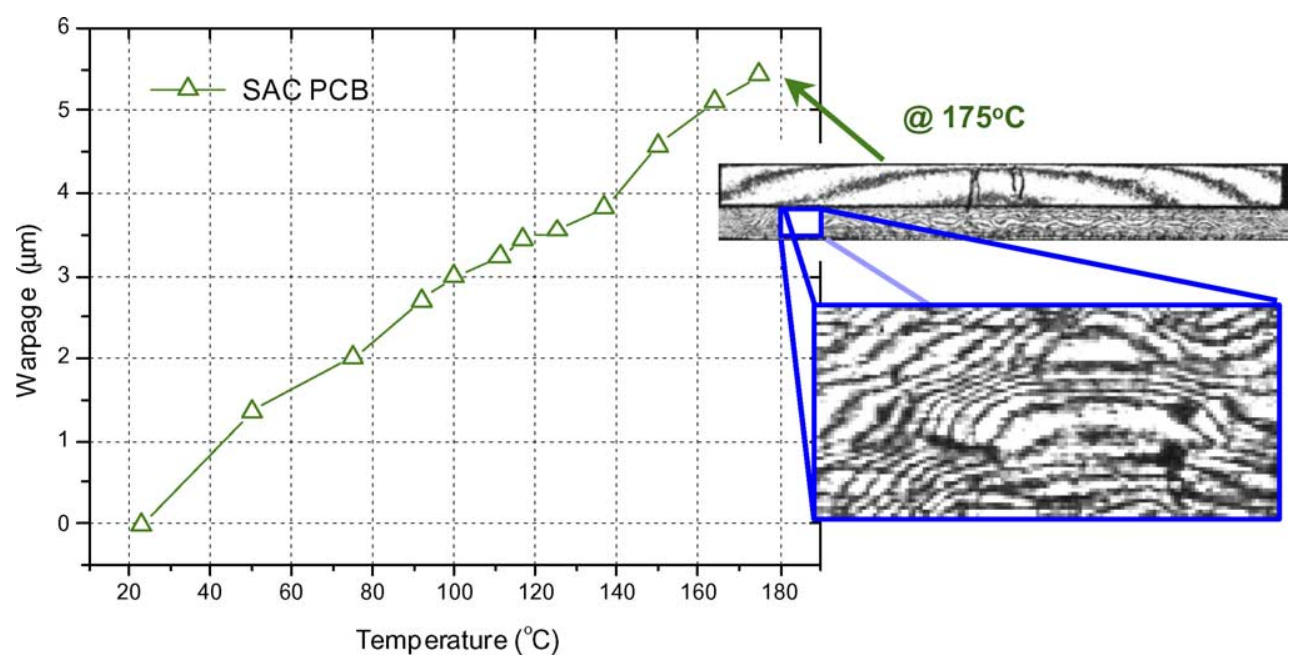

Fig. 11. Warpage variation measured by thermal relaxation test for SAC PCB up to $175^{\circ} \mathrm{C}$.

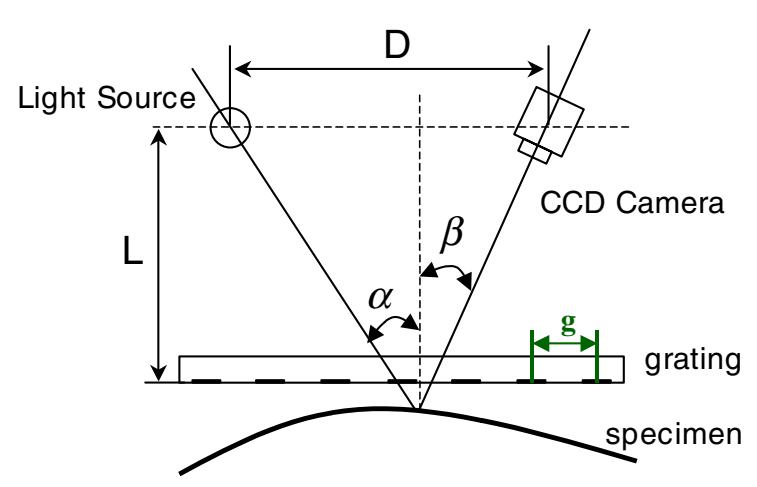

Fig. 12. Typical schematic design for shadow Moiré system.

gratings. Fig. 12 is a typical schematic design for shadow Moiré system. The governing equation of the out-ofplane displacement can be expressed as the following:

$W=\frac{g}{\tan \alpha+\tan \beta} N_{z}$

where $g$ is the grating pitch, $N_{z}$ is the fringe order, $\alpha$ is the incident angle, and $\beta$ is the viewing angle. If the CCD camera and light source are separated by the distance $D$ and located at the identical distance $L$ from the grating, by the following relation:

$\tan \alpha+\tan \beta=\frac{D}{L}$

Eq. (5) is simplified to

$W=\frac{g L}{D} N_{z}$

Basic sensitivity,

$\eta=\frac{g L}{D}$ which refers to the minimum relative displacement the system can optically resolve, is usually set to be 10 $100 \mu \mathrm{m} /$ fringe for shadow Moiré. Sensitivity can be enhanced up to sub-micron level by adopting phase shifting module and imposing related image processing schemes. However, intrinsic non-linearity of phase shifters and dependence of image processing on test conditions may cause adverse affects to the accuracy and repeatability of the system. Thus, in this work, optical sensitivity is elevated by introducing 200 lines $/ \mathrm{mm}$ ( $5 \mu \mathrm{m}$ pitch) quartz glass grating so that the warpage of SAC PCB can be measured which is expected to be around $7 \mu \mathrm{m}$. Fig. 13 shows the shadow Moiré setup. Collimated, monochromatic $(\lambda=632.8 \mathrm{~nm})$ laser source

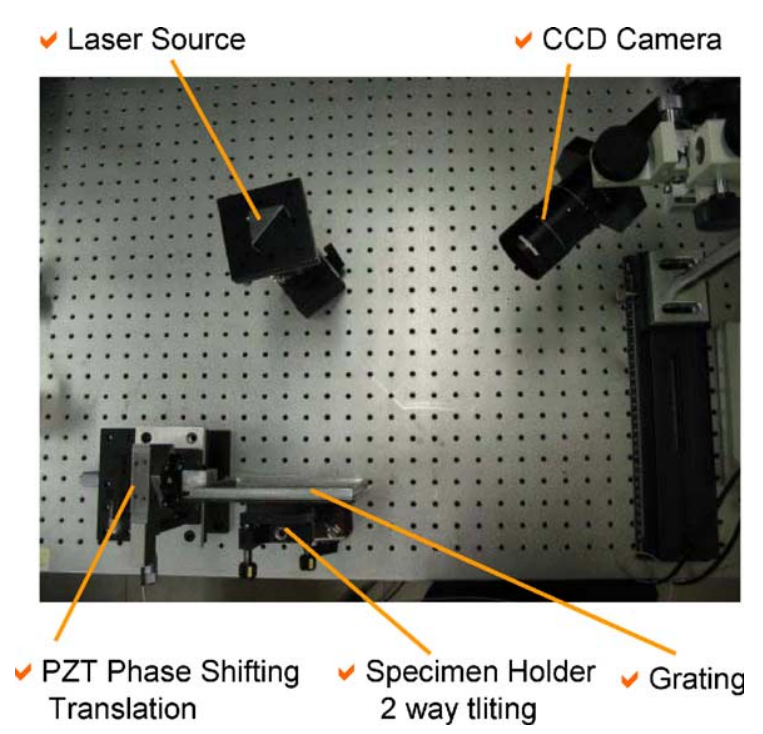

Fig. 13. Feature of shadow Moiré setup for this study. 

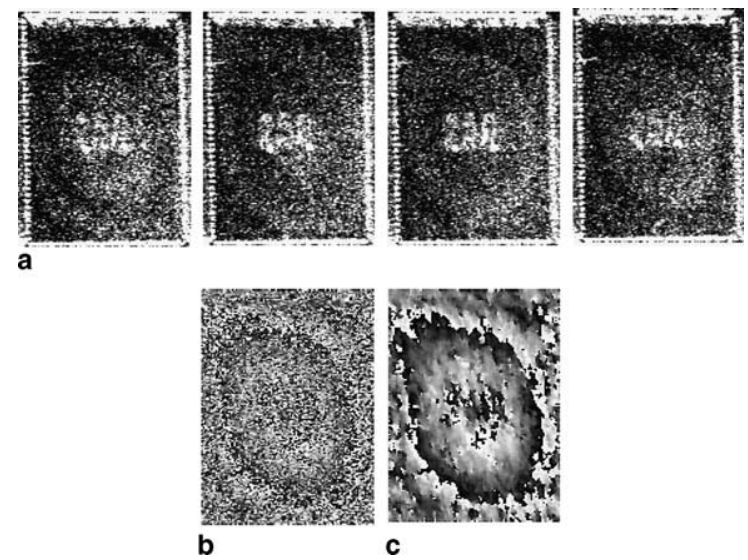

Fig. 14. Residual warpage of SAC PCB measured by fine pitch shadow Moiré method: (a) phase shifted images; (b) phase map; (c) filtered phase map.

is applied for the light source and the sensitivity is fixed to be $5 \mu \mathrm{m} /$ fringe by selecting the incident angle, $\alpha=0^{\circ}$ and viewing angle, $\beta=45^{\circ}$.

The shadow Moire fringe shown in Fig. 14(a) revealed poor contrast or visibility, thus, it is phase shifted to obtain the phase map for clear fringe counting (Fig. 14(b) and (c)). The estimated amount of warpage, $7.0 \pm 0.3 \mu \mathrm{m}$, is in good agreement with the previous data.

\section{Discussion}

It is found that different amount of residual warpage of chip and PCB is developed for different solder alloys after the solder reflow process (Table 1). In either solders, SAC or SP, chip and PCB are obliged to warpage due to CTE mismatch during cooling process. During their warped state, solder joints are in mixed mode stress condition, normal tensile (=peel) and shear existing at the same time. However, in SP, warpage is easily

Table 1

Residual warpage measurement results $(\mu \mathrm{m})$

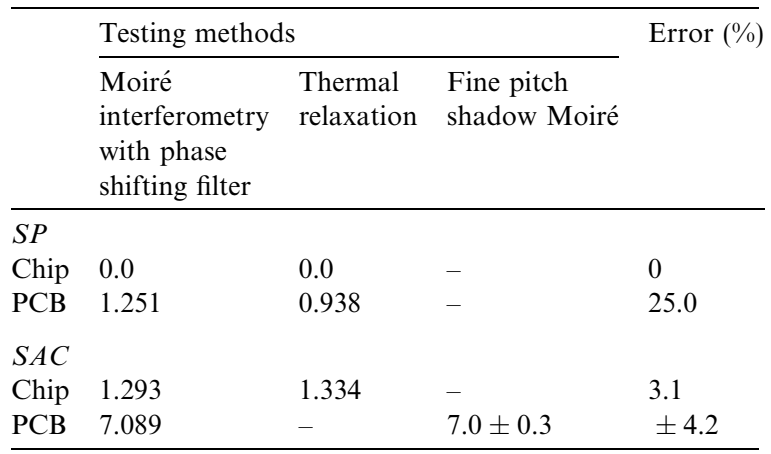
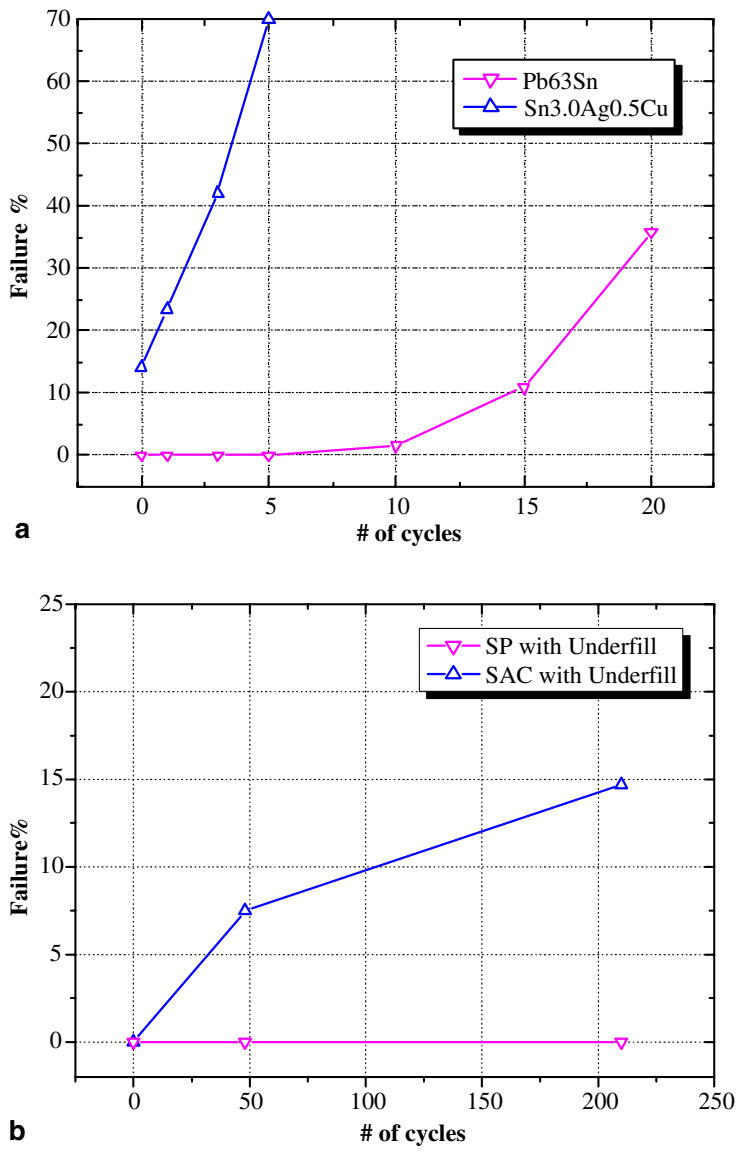

Fig. 15. Thermal cycling life data for SAC vs. SP $\left(-55^{\circ} \mathrm{C}\right.$ to $+125^{\circ} \mathrm{C}$ ): (a) Without underfill case; (b) With underfill case.

decreased due to relaxation of stresses (both normal and shear) and creep deformation in shear, leading the package to nearly pure shear state. For SAC which relatively relax and creep less than SP, remains in warped state, still carrying significant amount of stresses. Normal stress can be identified as the main cause of early fracture failure of flip-chips without underfill. It acts normal to the crack fronts and the resulting opening mode crack propagation conditions are mostly responsible for the failure [10]. Even if solder bump failure due to board warpage is not immediate, weakened bumps can pose a serious reliability risk [8].

According to thermal cycling test results of Fig. 15, non-underfilled SAC which has about five times larger warpage difference than SP, starts to fail from the first cycle with much faster failure rate. The typical failure mode for SAC is observed to be the brittle failure at $\mathrm{Al} / \mathrm{Ni}$ interface while for $\mathrm{SP}$ is found to be solder fatigue near UBM (Fig. 16).

As it was mentioned earlier underfill provides a significant (at least one order of magnitude) enhancement in solder joints reliability [3,5-7,9-12]. However, the 

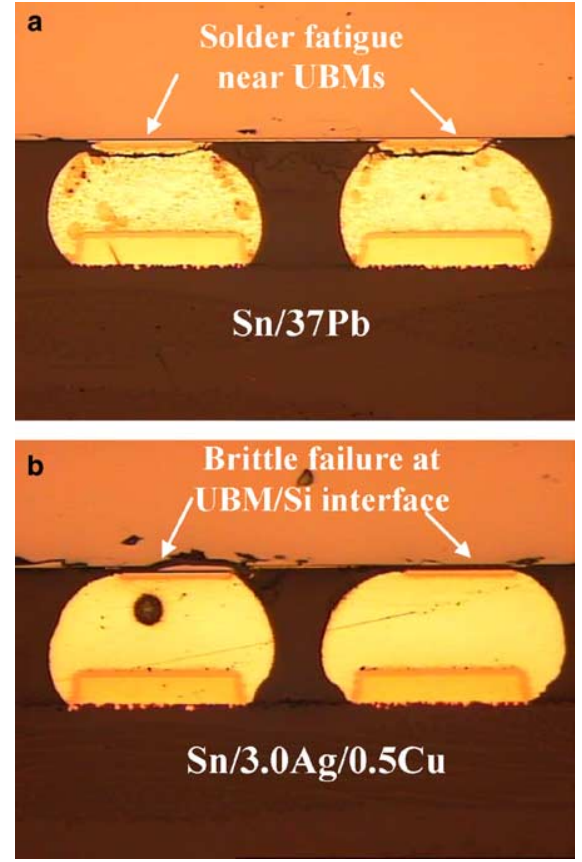

Fig. 16. Failure analysis with optical microscope after several thermal cycles (without underfill case): (a) SP after 20 cycles; (b) SAC after 3 cycles.

reliability of SAC is still poor even with underfill. Dissimilar to underfilled SP which lasts for 1000 thermal cycles without any failure, $30 \%$ of the specimens are failed after 100 cycles through crack propagation at UBM/Al interface and IMC region for SAC (Fig. 17). It can be surmised that high normal strain/stress may have caused crack to propagate readily through brittle interface and material in SAC. This mechanism is revealed as high failure rate for SAC either it is underfilled or not.

To meet the future needs of high pin count and high performance, the LSI die and package size of flip-chip devices is constrained to become larger [3]. Besides, many of the products that use flip-chips use relatively thin substrate $(0.5-1.0 \mathrm{~mm})$, which increases board flexure during manufacturing process [8]. Moreover, to fulfill the environment issues SAC will be replacing SP in near future. In order to guarantee the reliability of solder joints for flip-chip using SAC, it is crucial to accurately quantify and control the residual warpage, as it is discussed in this work. There exists several parameters affecting the residual warpage during reflow process. Residual stress is expected to diminish if the bending stiffness or compliance of chip and PCB are matched. This can be achieved by varying the thickness of the two adherends at the early design stage. A solder alloy with superior stress relaxation nature is preferred to reduce the residual stress, such as SP. Moreover, subsequent relaxation through thermal aging process is

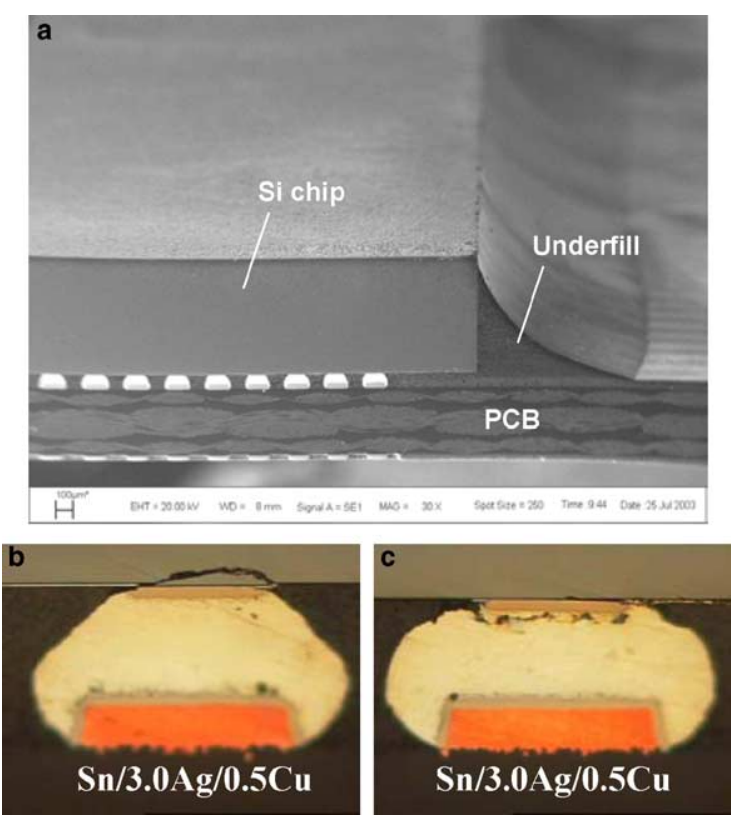

Fig. 17. Flip-chip with underfill case: (a) SEM image of underfilled flip-chip before thermal cycling; (b) optical microscope inspection for SAC after 100 cycles-Si cratering and UBM/Al failure; (c) crack along IMC.

anticipated to decrease the residual stress effectively. Besides, lowering the peak temperature and reducing the cooling rates during solder reflow process can also contribute to mitigate the residual stresses.

\section{Conclusions}

Several experimental techniques to measure small residual warpages $(0-10 \mu \mathrm{m}$ range $)$ are suggested and its significance on reliability of entire flip-chip package is discussed.

1. Residual warpage of chip and PCB are measured for both $\mathrm{Sn} / 37 \mathrm{~Pb}$ and $\mathrm{Sn} / 3.0 \mathrm{Ag} / 0.5 \mathrm{Cu}$ by Moiré interferometry. The gratings are replicated on the chip and PCB separately and the $V$ field is observed after the solder reflow.

2. A phase shifting filter is developed which enables accurate fringe counting in spite of high level of noises. The algorithm is effectively applied by discriminating the data from low and high frequency noises.

3. A new approach to measure residual warpage is proposed by thermally relaxing the specimen. The result is mutually verified with that of other methods.

4. Shadow Moiré setup which can resolve $5 \mu \mathrm{m} /$ fringe sensitivity is developed by adopting fine pitch grating (200 lines/mm) with collimated laser beam. 
5. Residual warpage values measured in this study are summarized in Table 1. The amount of residual warpage and stress induced during reflow process should be considered at early design stage. Proper control of residual warpage and stress through geometry, material, and process modification mentioned in this work can remarkably increase the reliability of flip-chip packages.

\section{Acknowledgment}

This work has been supported by Computer Aided Reliability Evaluation (CARE) for Electronic Packaging-National Research Laboratory (NRL) program.

\section{References}

[1] Suhir E. The future of microelectronics and photonics and the role of mechanics and materials. ASME J Electron Packag 1998;120(1):1-11.

[2] Chiang KN, Liu ZN, Peng CT. Parametric reliability analysis of no-underfill flip chip package. IEEE Trans Comp Packag Technol 2001;24(4):635-40.

[3] Sawada Y, Harada K, Fujioka H. Study of package warp behavior for high-performance flip-chip BGA. Microelectron Reliab 2003;43:465-71.

[4] Michaelides S, Sitaraman SK. Die cracking and reliable die design for flip-chip assemblies. IEEE Trans Adv Packag 1999;22(4):602-13.

[5] Chen L, Zhang Q, Wang G, Xie X, Cheng Z. The effects of underfill and its material models on thermomechanical behaviors of a flip chip package. IEEE Trans Adv Packag 2001;24(1):17-24.

[6] Suryanarayana D, Hsiao R, Gall TP, McCreary JM. Encapsulation of flip chip fatigue life by encapsulation. IEEE Trans Comp Hybrids Manufact Technol 1991;14(1): 218-23.

[7] Clemnti J, McCreary J, Niu TM, Palomaki J, Varcoe J, Hill G. Flip-chip encapsulation on ceramic substrates. In: Proceedings of 43rd electronic components and technology conference 1993, ECTC'93. p. 175-81.

[8] Chengalva MK, Jeter N, Baxter SC. Effect of circuit board flexure on flip chips before underfill. In: Proceedings of 50 th electronic components and technology conference 2000, ECTC'00. p. 657-65.

[9] Cai X, Chen L, Zhang Q, Xu B, Huang W, Xie X, et al. Quantitative mechanism of significant benefits of underfill in flip-chip assemblies. ASME J Electron Packag 2003;125: 84-92.

[10] Rzepka S, Korhonen MA, Meusel E, Li CY. The effect of underfill and underfill delamination on the thermal stress in flip-chip solder joints. ASME J Electron Packag 1998;120: 342-8.

[11] Zhang W, Wu D, Su B, Hareb SA, Lee YC, Masterson BP. The effect of underfill epoxy on warpage in flip-chip assemblies. IEEE Trans Comp Packag Manufact Technol-Part A 1998;21(2):323-9.

[12] Su P, Rzepka S, Korhonen M, Li CY. The effects of underfill on the reliability of flip chip solder joints. J Electron Mater 1999;28(9):1017-22.

[13] Madenci E, Shkarayev S, Mahajan R. Potential failure sites in a flip-chip package with and without underfill. ASME J Electron Packag 1998;120:336-41.

[14] Gektin V, Bar-Cohen A, Ames J. Coffin-manson fatigue model of underfilled flip-chips. IEEE Trans Comp Packag Manufact Technol-Part A 1997;20(3):317-26.

[15] Gektin V, Bar-Cohen A, Witzman S. Coffin-manson based fatigue analysis of underfilled DCAs. IEEE Trans Comp Packag Manufact Technol-Part A 1998;21(4):577-83.

[16] Nyaether JB, Lundstrom P, Liu J. Measurements of solder bump lifetime as a function of underfill material properties. IEEE Trans Comp Packag Manufact Technol-Part A 1998;21(2):281-7.

[17] Yeh CP, Ume C, Fulton RE, Wyatt KW, Stafford JW. Correlation of analytical and experimental approaches to determine thermally induced PWB warpage. IEEE Trans Comp Hybrids Manufact Technol 1993;16(8):98695.

[18] Qun Z, Xiaoming X, Liu C, Gouzhong W, Zhaonian C, Kempe W. On the degradation of the solder joints of underfilled flip chip packages: a case study. Soldering Surf Mount Technol 2000;12(3):24-8.

[19] Lau JH, Lee SWR, Chang C. Effects of underfill material properties on the reliability of solder bumped flip chip on board with imperfect underfill encapsulants. IEEE Trans Comp Packag Technol 2000;23(2):323-33.

[20] Schubert A, Dudek R, Kloeser J, Michel B, Reichl H, Hauck $\mathrm{T}$, et al. Experimental and numerical reliability investigations of FCOB assemblies with process-induced defects. In: Proceedings of 50th electronic components and technology conference 2000, ECTC'00. p. 624-32.

[21] Lau JH, Lee SWR. Fracture mechanics analysis of low cost solder bumped flip chip assemblies with imperfect underfills. ASME J Electron Packag 2000;122:306-10.

[22] Gu Y, Nakamura T. Interfacial delamination near solder bumps and UBM in flip-chip packages. ASME J Electron Packag 2001;123:295-301.

[23] Liu S, Mei Y. Behaviors of delaminated plastic IC packages subjected to encapsulation cooling, moisture absorption and wave soldering. IEEE Trans Comp Packag Manufact Technol-Part A 1995;18(3):634 45.

[24] Wang J, Ren W, Zou D, Qian Z, Liu S. Processing mechanics for flip-chip assemblies. Comput Struct 1999;71: 457-68.

[25] Wiese S, Feustel F, Meusel E. Characterization of constitutive behaviour of $\mathrm{SnAg}, \mathrm{SnAgCu}$ and $\mathrm{SnPb}$ solder in flip chip joints. Sensors Actuat A 2002;3289:1-6.

[26] Wiese S, Schubert A, Walter H, Dudek R, Feustel F, Meusel E, et al. Constitutive behaviour of lead-free solders vs. lead-containing solders-experiments on bulk specimens and flip-chip joints. In: Proceedings of 51st electronic components and technology conference 2001, ECTC'01, p. 890-902.

[27] Amagai M, Watanabe M, Omiya M, Kishimoto K, Shibuya T. Mechanical characterization of Sn-Ag-based lead-free solders. Microelectron Reliab 2002;42:951-66. 
[28] Sasaki K, Yanagimoto A, Ishikawa H. Effect of lead and lead-free solders on bend of substrate. In: Proceedings of advanced technology in experimental mechanics 2003, ATEM'03, OS10W0040.

[29] Liu S, Mei Y, Wu TY. Bimaterial interfacial crack growth as a function of mode-mixity. IEEE Trans Comp Packag Manufact Technol-Part A 1995;18(3):618-26.

[30] Liu S, Zhu JS, Hu JM, Pao YH. Investigation of crack propagation in ceramic/conductive adhesive/glass systems. IEEE Trans Comp Packag Manufact Technol-Part A 1995;18(3):627-33.

[31] Wang J, Qian Z, Liu S. Process induced stresses of a flipchip packag by sequential processing modeling technique. ASME J Electron Packag 1998;120:309-13.

[32] Yeung DTS, Yuen MMF. Warpage of plastic IC packages as a function of processing conditions. ASME J Electron Packag 2001;123:268-72.

[33] Palaniappan P, Baldwin DF. In process stress analysis of flip-chip assemblies during underfill cure. Microelectron Reliab 2000;40:1181-90.

[34] Driel WD, Zhang GQ, Janssen JHJ, Ernst LJ, Su F, Chian $\mathrm{KS}$, et al. Prediction and verification of process induced warpage of electronic packages. Microelectron Reliab 2003;43:765-74.

[35] Polsky Y, Sutherlin W, Ume IC. A comparison of PWB warpage due to simulated infrared and wave soldering processes. IEEE Trans Electron Packag Manufact 2000; 23(3):191-9.

[36] Stiteler MR, Ume IC, Leutz B. In-process board warpage measurement in a lab scale wave soldering oven. IEEE Trans Comp Packag Manufact Technol-Part A 1996; 19(4):562-9.

[37] Chien CH, Chen YC, Chiou YT, Chen T, Hsieh CC, Yan $\mathrm{JJ}$, et al. Influences of the moisture absorption on PBGA package's warpage during IR reflow process. Microelectron Reliab 2003;43:131-9.

[38] Post D, Han B, Ifju P. High sensitivity Moiré. New York: Spring-Verlag; 1994.

[39] Karalekas D, Aggelopoulos A. Study of shrinkage strains in stereolithography cured acrylic photopolymer resin. J Mater Process Technol 2003;136:146-50.

[40] Lin TY, Njoman B, Crouthamel D, Chua KH, Teo SY, Ma YY. The impact of moisture in mold compound performs on the warpage of PBGA packages. Microelectron Reliab 2004;44:603-9.

[41] Ding H, Powell RE, Hanna CR, Ume IC. Warpage measurement comparison using shadow Moiré and projection Moiré methods. In: Proceedings of 52nd electronic components and technology conference 2002, ECTC'02. p. 176-82.

[42] Bhattacharya SK, Ume IC, Dang AXH. Warpage measurement of large area multitilted silicon substrates at various processing conditions. IEEE Trans Comp Packag Technol 2000;23(3):497-504.

[43] Voloshin AS, Tsao PH, Pearson RA. In situ evaluation of residual stresses in an organic die-attach adhesive. ASME J Electron Packag 1998;120:314-8.

[44] Stout EA, Sottos NR, Skipor AF. Mechanical characterization of plastic ball grid array package flexure using
Moiré inteferometry. IEEE Trans Adv Packag 2000; 23(4):637-45.

[45] Cho SM, Cho SY, Han B. Observing real-time thermal deformations in electronic packaging. Exp Tech 2002; 26(3):25-9.

[46] Guo Y, Woychik CG. Thermal strain measurement of solder joints in second level interconnections using Moiré interferometry. ASME J Electron Packag 1992;114(1): 88-92.

[47] Han B. Thermal stresses in microelectronics subassemblies: quantitative characterization using photomechanics methods. J Thermal Stresses 2003;26(6):1-16.

[48] Kwon WS, Yang SY, Lee SB, Paik KW. The effect of $T_{\mathrm{g}}$ on thermo-mechanical deformation and reliability of adhesive flip chip assemblies during temperature cycling. In: Proceedings of 54th electronic components and technology conference 2004, ECTC'04. p. 1731-7.

[49] Yang SY, Lee SB, Kwon WS, Paik KW. Analytical approach to evaluate shear stress in flip chip interconnection using NCA/ACF. In: Proceedings of 4th international symposium on electronic materials and packaging 2002, EMAP2002. p. 415-20.

[50] Wen Y, Basaran C. An analytical model for thermal stress analysis of multi-layered microelectronics packaging. Mech Mater 2004;36:369-85.

[51] Guo Y, Liu S. Development in optical methods for reliability analysis in electronic packaging applications. ASME J Electron Packag 1998;120:186-93.

[52] Han B, Guo Y, Lim CK, Caletka D. Verification of numerical models used in microelectronics packaging design by interferometric displacement measurement methods. ASME J Electron Packag 1996;118:15763.

[53] Verma K, Park SB, Han B. On the design parameters of flip-chip PBGA package assembly for optimum solder ball reliability. IEEE Trans Comp Packag Technol 2001;24(2): 300-7.

[54] Verma K, Han B. Warpage measurement on dielectric rough surfaces of microelectronics devices by far infrared fizeau interferometry. ASME J Electron Packag 2000;122: 227-32.

[55] Du Y, Zhao JH, Ho P. An optical method for measuring the two-dimensional surface curvatures of electronic packages during thermal cycling. ASME J Electron Packag 2001;123:196-9.

[56] Kim JS, Paik KW, Seo HS. A quantitative analysis of the stress relaxation effect of thermoplastics in multilayer substrates. IEEE Trans Adv Packag 1999;22(4):63841.

[57] Suhling JC, Lin ST. Application of optical methods to electronic packaging. Applicat Exp Mech Electron Packag ASME 1995;EEP-13/AMD-214:39-45.

[58] Miyake K, Yoshida T, Baik HG, Park SW. Viscoelastic warpage analysis of surface mount package. ASME $\mathbf{J}$ Electron Packag 2001;123:101-4.

[59] Kong JWY, Kim JK, Yuen MMF. Warpage in plastic packages: effects of process conditions, geometry and materials. IEEE Trans Electron Packag Manufact 2003;26(3):245-52. 